\title{
Study on the Building of Mobile Platform for Independent Learning Based on Android
}

\author{
Xiao Liyan ${ }^{1}$ \\ ${ }^{1}$ College of Foreign Language, Jishou University, \\ Zhanjiajie, China
}

\author{
Dong Jianfeng ${ }^{2}$ \\ ${ }^{2}$ College of Tourism Management, Jishou University, \\ Zhanjiajie, China
}

\begin{abstract}
This paper analyzes the key technologies of building mobile platform for independent learning, constructs an independent platform based on Android, and discusses the main functional module and implementation. Experimental research shows that students can study and exchange anytime and anywhere through this platform, thus breaking the limitation on space, time and equipment of traditional education, and finally improving learning efficiency.
\end{abstract}

Keywords: Android; mobile independent learning; mobile platform for learning

\section{Introduction}

Recently, with the development and application of modern network technology and mobile communication technology, the new method of independent learning based on network and information technology is increasingly welcomed in the current era of knowledge-driven economy. Mobile independent learning first dated from the practical exploration to network education and e-campus construction in abroad ${ }^{[1]}$. In 1990, Kenneth Green, professor of Claremont University in America, launched the Campus Computing Project, and on basis of this he built a new model of digital platform for learning. Hereafter, more than 3000 colleges and universities have transformed their traditional teaching to digital platform teaching ${ }^{[2]}$, and gradually led their students to carry out independent learning through this platform. Thereunto, Business platform such as Learning Space, Top class, and Blackboard etc and open-source platform such as Moodle, Atutor, Claroline, Sakai, LAMS and so on, are very typical.

As the open-source smartphone platform developed by Google, Android conducted application development through Java technology and provided abundant APIs so that it could combine with modern mobile teaching idea, which could make users enter teaching system efficiently and easily to learn teaching courseware, thus optimizing and advancing their own knowledge structure comprehensively. The key technology of mobile independent learning platform

\subsection{The development mode of mobile learning platform}

Generally speaking, there are three application development modes applied in the developing of traditional network teaching platform: stand-alone client mode, B/S mode, and $\mathrm{C} / \mathrm{S}$ mode ${ }^{[3]}$. And all of them can support the development of mobile independent learning platform technologically.

(1)Stand-alone client mode refers to completely installing mobile service content(such as learning courses or procedures) into mobile terminal device. Such method would larger client program. So users can access to the mobile content services even without networking after installing and operation.

(2)Thin client/server $(\mathrm{B} / \mathrm{S})$ mode means to get in server content through typing in HTTP in browser, thus it's not necessary to install any program in mobile terminal.

(3)Thick client/server(C/S) is to install and configure a function-rich and interactive-design user interface. Thick client, in fact, is just mobile phone client in mobile terminal, especially in smart phone terminal. $\mathrm{C} / \mathrm{S}$ mode has just combined the performance advantages of stand-alone client and thin client and server. Specifically, compared with the traditional $\mathrm{B} / \mathrm{S}$ mode, what's more important is that users can customize their own interface and operation based on business program. Especially, in mobile client interface, users can have a better experience, because it is not necessary to transmit data in program interface or graphic representations so that it could save data traffic of mobile communication, thus saving cost or even supporting offline service. Moreover, mobile phone client would help smart terminal exert its function completely and comprehensively.

\subsection{Platform content presentation technology}

In the mobile learning platform based on $\mathrm{C} / \mathrm{S}$ mode system structure, there are two content formats, namely, text plus streaming media and animation. And text plus streaming media can be edited by reference to the way of editing XML, which means that it's not too difficult to edit server content. Animation covers Flash animation and SVG animation. Flash animation is peculiar to its time slice segmentation and reconfiguration technology, and meanwhile it's connected with the object of Action Script 
and flow control, which could make interface design and animation design more flexible. SVG, based on XML, is a kind of graphic format used to describe vector graphics. SVG can be defined or triggered directly through statement or script, or SVG is through scripting language calling object model to have access to and control the properties and attribute value of every element.

\subsection{Android thick client technology}

The important parts of Android thick client technology are Activity and Intent, forming the page container and screens switch of this system. Page layout can be realized by adopting XML files. And layout technology (LinearLayout 、 TableLayout etc) and related controllers (Button、 TextView etc), provided by Android, are used to finish page design. Meanwhile, XML layout files are loaded in Activity to display and coordinate with Intent to realize the turning of pages. Then event trigger technology, provided by Java, is also used to finish button clicks.

Android client conducted network communication with server-side remotely through HttpClient and some related technology, including transmission request and response order, to realize real-time interaction between client and server. Sqlite is used to store data in client.

In particular, Structs component, based on MVC design patterns, is used to realize function division of web serverside. MVC's meaning is expressed as model, view, and controller. Model level is usually used to realize service logic in system by adopting JavaBean or EJB, while View level is used to interact with users by adopting JSP designing. And Controller level, being the communication medium between Model and View, can allocate user's request and choose proper view to display, meanwhile it can also explain user's input and map it as executable operation in Model level. In general, MVC is a design mode and can compulsorily separate the input, processing and output of application program.

\section{Designing of Mobile Platform for Independent Learning Based on Android}

\subsection{Server-side technology}

According to the system requirements, it adopts $\mathrm{C} / \mathrm{S}$ architecture, whose details are shown in figure 1. Mobile learning terminal acquires course learning resources and related information by web service. Once web service receives requirements from clients, it surfs on database and acquires needed resources or information, and then returns disposed results to clients. The server management system takes charge of managing dynamic data such as clients, student information, course information, course resources and learning schedule.

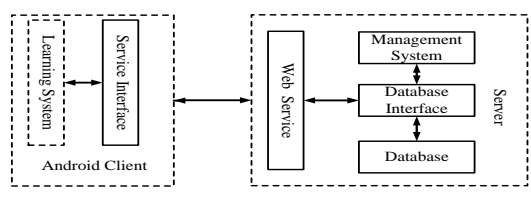

Fig. 1: C/S architecture of the platform

\subsection{Designing of Functional Structure}

Mobile platform consists of PC management terminal and mobile learning terminal. PC management terminal is mainly for managers to realize back-stage management and for teachers to publish information. Mobile learning terminal is mainly for students possibly to study anytime and anywhere by wifi or mobile base station. After integrating platform requirements, here is structure diagram of mobile learning platform as following, details in figure 2 .

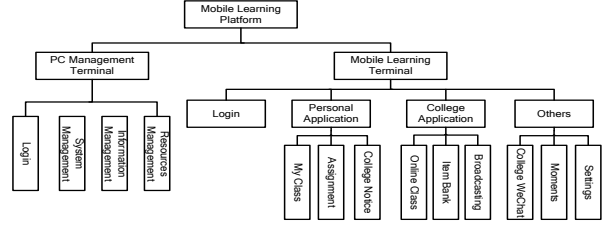

Fig. 2:Function structure of the platform

\subsection{Designing of PC Management Terminal}

In Fig.3, Users of PC management terminal are managers and teachers. Managers distribute user authority in PC management terminal, including class distribution for guiding teachers (counselors) to control and course distribution for teachers to teach. Guiding teachers mainly release information, while teaching teachers upload teaching resources. ${ }^{[4]}$ On the basis of this, PC management terminal design can equipped with main modules as following: Login module can provide different corresponding operations when different system users login. Users login by the real-name system and do not need user registration again. All information of teachers is directly matched by back-stage database. Users can access to corresponding management interface by the teacher identity they input. Teachers newly appointed should be input into teacher system database by managers.

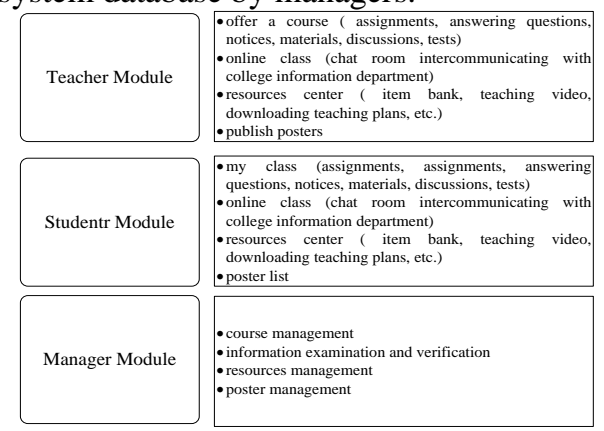

Fig. 3: PC management terminal

System management module is mainly for managers to assign user authority of modules, teachers and student. Besides, it makes comprehensive and regular maintenance 
on personnel base, including searching, adding and deleting information. Information management module is mainly open to guiding teacherswho can manage information of classes, including proceeding students' scores, altering, deleting, class notice and latest information.

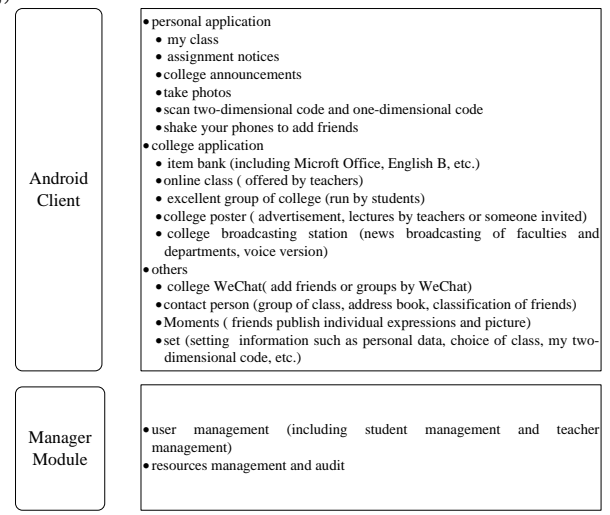

Fig. 4: Mobile learning terminal

Resource management module is mainly for teaching teachers to manage resources of their own course, including operations such as adding, deleting or changing text and video resources.

\subsection{Designing of Mobile Leaning Terminal}

As shown in Fig.4, users of mobile learning terminal are teachers and students. Students also do not need registration when they login this platform, but input their own student number and password in login interface of mobile terminal, and at the same time, operate students base matching. Matching successfully means that student users login successfully. After uploading they will access to system main interface, showing in the following picture. Sign of mobile application success is whether it can provide an exceptional user experience (UE) or not. Therefore, UE takes a prior role in designing system. "Fast, response and seamless" are three important features that the best UE should have, namely, operating fast, responding quickly, and interacting properly.

\subsection{Designing of Functional Modules}

General speaking, the internet teaching-learning platform should provide functions such as learning, testing and reviewing online class, sharing resources and item bank, and downloading teaching plans for teachers or students. According to our survey on mobile independent learning platform and combining with requirements of school developing mobile independent learning, we design three role function modules of teacher, student and manager, respectively (as following picture). Main functions include:

(1) College question bank. It can upload and download, and also achieve online reading of Word、Excel、PPT、 TXT files. Besides, it has preliminarily achieved online reading of college English question bank.

(2) Online class. Teacher terminal can complete online class release including publishing courseware, teaching plans, assignments and test questions, and student management; moreover it has function of sponsoring chat immediately. Student terminal can achieve elective function, at the same time, check information released by teachers such as courseware or teaching plans, and also can leave a message.

(3) College notice. In this part, users can publish news and notices. Meanwhile, users can manage information, including adding, changing, deleting, increasing, of course, reading online.

(4) College poster. Here users can release posters and upload poster pictures and character poster, meanwhile, manage posters properly.

(5) College broadcasting station. Users can publish or listen to broadcasting (voice) on line, and also manage broadcasting information systematically.

Main function module of mobile learning platform shows as following picture.

\section{Analysis of the application of mobile independent learning based on Android}

JSULP ( Learning Platform for Jishou University), developed based on Android, is a platform for mobile learning, already applied in English learning and Ecommerce by professional students. As shown in Fig.5, platform has integrated the functions from school notice to student independent learning, and having integrated with Wechat client etc.

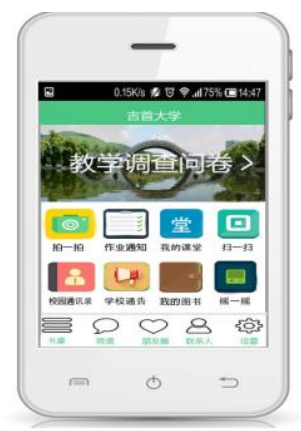

Fig. 5: Interface of JSULP

According to its application in students, this platform's page view has reached to more than 200 times from the survey to each specialty. Students and teachers can exchange and answer questions in this platform, This learning platform could let students and teachers exchange with each other without time and space limitation of 24 hours per day, breaking the traditional teaching model and having unexampled advantages.

\section{Conclusion}

At present, the study on mobile network learning platform is still in initial stage. So how to make it more humanity to further meet the needs of learners? And how to optimize and update teaching content according to the 
learning characteristics of mobile platform and apply it into other fields outside colleges and universities? Therefore, the primary research direction, for now and future, is to develop the new model of achieving education for all based on this mobile platform. The Android mobile learning platform, successfully researched and developed this time, mainly features in good inter-activeness, convenient resource updating, and low-consuming data traffic etc. To this end, the mobile learning platform, based on Android, can be widely applied in smart phone, pad, or other portable set, providing a new channel to contact learning resource, thus it would bear much practical value and reference value to conduct a deep research on mobile learning system.

\section{Acknowledgment}

This paper is supported by project of Hunan provincial education and science "Twelfth Five-Year Plan" annual issue under grant XJK015BXX006.

\section{References}

[1] Use He Tianlan,Yang Xinju. Research of Mobile Network Learning Platform based on Android. INTELLIGENT COMPUTER

AND

APPLICATION,2014,4.

[2] Lynch, B. Language Program Evaluation: Theory and Practi. Cambridge: Cambridge University Press, 1996.

[3] Li Lianjun.Designing and Realization of a Mobile Studying Systembased on J2ME and J2EE.MODERN COMPUTER,2010,11.

[4] http://jcpt.nhic.edu.cn/ 